\title{
From the workplace to the classroom: Examining the impact of self-leadership learning strategies on higher educational attainment and success
}

\author{
Uwe Napiersky and Stephen A. Woods
}

\section{Introduction}

Promoting and encouraging behaviour that enables people to develop and learn independently, continuously and reflexively through their careers, is a compelling and recurrent issue in learning and development. In this study, we examine this issue through the lens of models and theories of selfleadership (Manz, 2015), a concept from the management field that conceptualises and describes cognitive, motivational and behavioural factors that promote performance (Ho \& Nesbit, 2014). In this study, we explore how key aspects of self-leadership predict academic attainment longitudinally in a sample of business majors, demonstrating the potential benefits of for example, engaging in strategies for self-goal setting, self-management of behaviour and effort, being aware of one's motivation and adopting a positive outlook for academic attainment.

\section{Self-leadership}

Self-leadership is defined as an individual's capacity for improving their own performance through self-regulatory processes comprising cognitive, motivational and behavioural strategies. The essence of these mechanisms concerns how people lead themselves to perform naturally motivating tasks as well as those that are less motivating to them (Manz, 2015).

Behavioural strategies for self-leadership serve to direct and regulate individual performance and behaviour (Marques-Quinteiro \& Curral, 2012). These strategies involve setting oneself goals independently, self-observation of performance towards those goals, regulation of behaviour, and provision of self-reward (Neck \& Houghton, 2006). As strategies for self-management of performance, these strategies are consistent with theories of goal setting (Latham \& Locke, 2007) and self-regulation (Bandura, 1991).

The association of goal setting with enhanced motivation and performance is well established in the literature (see e.g. Latham \& Locke, 2007). Goals that are specific, stretching, measurable and time-bound result in enhanced performance (Woods \& West, 2014). This effect is observed because such goals serve to direct behaviour towards achieving a performance standard, maintain effort and persistence, and prompt the development of performance strategy goals. In self-leadership, self-goal setting involves setting objectives for personal achievement as well as performance standards that are aligned to the performance expectation of the team or organisation. It represents the tendency for people to set themselves specific objectives that have the features of effective goals that others set, and to be committed to their achievement. Contingent self-reward is proposed as an effective mechanism by which people stay motivated to achieve objectives (Neck \& Houghton, 2006), which is also consistent with the socalled high-performance cycle representation of goal setting (Latham \& Locke, 2007). In this cycle, contingent reward fosters a cycle of greater commitment to new goals and objectives.

Three key processes underpin self-regulation (Bandura, 1991). These are self-monitoring, self-judgement and affective self-reaction. Self-regulation therefore concerns monitoring one's behaviour, and managing it such that positive self-reactions are maintained, and negative self-reactions reduced. In the context of goal setting, selfregulation is associated with establishing goals, planning to achieve them, striving to achieve them, and importantly, revision to behaviour and engagement with the goal (Vancouver \& Day, 2005). Goals that are regulated, by definition, internalised states to be attained. Selfregulation serves to enable people to monitor their progress and act to modify effort and behaviour in order to achieve their goals. 
In sum, behavioural aspects of self-leadership align well to these theoretical frameworks, describing the self-setting of goals with self-administered contingent reward attached to their achievement, combined with effective selfregulatory processes (behavioural observation and reflection, and self-direction of behaviour).

Cognitive aspects of self-leadership involve invoking constructive thought patterns designed to encourage attainment of goals (Prussia, Anderson, \& Manz, 1998), and growth motivation (Neck, Houghton, Sardeshmukh, Goldsby, \& Godwin, 2013). These include visualising successful goal achievement, and positive self-talk (i.e. coaching or encouraging onself in one's mind or out loud).

Motivational aspects of self-leadership have tended to focus on intrinsic motivation (Prussia et al., 1998) as a result of deriving enjoyment from the content of work. Changing perceptions of work tasks to increase for example perceived control and meaningfulness, can foster positive intrinsic motivation, and is associated with greater engagement (Woods \& Sofat, 2013).

However, contemporary writing on self-leadership (e.g. Manz, 2015) increasingly emphasises the role of affective constructs, consistent with positive psychology (Peterson, 2006) and in particular, psychological capital (Luthans, Youssef, \& Avolio, 2007). Psychological capital is a positive psychological state of development that comprises, selfefficacy (confidence in one's capability), optimism (having a positive outlook, and feeling in control of success), resilience (responding effectively to setbacks) and hope (persevering towards goals). Research shows that job performance and satisfaction are associated with psychological capital (Luthans et al., 2007), and relevant for selfleadership behaviour. For example, Prussia et al. (1998) found that self-efficacy mediated the relationship of selfleadership with performance.

\section{Self-leadership in the context of learning and development}

Self-leadership represents an overarching and evolving framework for performance enhancing selfbehaviours, cognitions and motivational states that collectively enable enhance self-control over performance and behaviour. The organisational and management literature includes empirical studies of self-leadership showing it to predict higher performance at work (e.g. Ho \& Nesbit, 2014; Prussia et al., 1998). In military settings, self-leadership has also been found to enhance performance and training achievements (Lucke \& Furtner, 2015).

No research has previously examined self-leadership in the context of higher education learning and development. Yet, the processes of self-leading to attain effectiveness and performance at work could similarly apply to the attainment of educational, learning and developmental outcomes. The advantage in an educational setting is that self-leadership strategies may not only enhance attainment in the short-term, but also represent competencies and skills for life-long learning. Numerous significant working life outcomes are associated with self-leadership including higher productivity, psychological empowerment, job satisfaction and career success, and lower absenteeism and stress (Stewart, Courtright, \& Manz, 2011).

Although there is no direct examination of the effects of self-leadership on educational attainment in the literature, there are conceptual and empirical reasons to support the idea of the positive association of self-leadership with learning outcomes. For example, Sitzmann and Johnson (2012) found that interventions to help people plan their development were only effective when accompanied by interventions to promote self-regulation, suggesting the role of self-monitoring of learning and developing needs as important regulatory processes in learning.

In educational settings, processes included within self-leadership have been associated with educational outcomes, showing that particular styles of goal setting and opportunity to self-evaluate (or self-reflect) enhanced self-efficacy and use of self-regulation (Schunk \& Ertmer, 1999). Strivens and Ward (2013) describe ways that student selfreflection may be incorporated into learning strategies. More broadly, processes such as self-regulation, selfmotivation and self-reflection are included under the umbrella of personal development planning, the benefits of which have been shown in numerous studies with educational criteria such as attainment (see Gough, Kiwan, Suttcliffe, Simpson, \& Houghton, 2003). The main limitation of past studies in the education literature is a lack of a coherent framework for individual self-learning strategies. Self-leadership could address this gap to provide greater insight into the combined effects of self-learning strategies. 
Literature on goal orientation differentiates learning (striving for mastery) from performance (striving to achieve performance standards avoiding failure) orientation (Dweck \& Leggett, 1988). Meta-analysis (Payne, Youngcourt, \& Beaubien, 2007) shows that learning goal orientation is associated with higher learning performance. However, the ways in which goals are set can foster a learning goal approach by promoting the adoption of learning strategies reflecting those of a learning goal orientation (Seijts, Latham, Tasa, \& Latham, 2004). Goal setting appears to be an effective mechanism for promoting learning and development. Extending this reasoning, self-goal setting could potentially have benefits for learning and development outcomes.

\section{The present study}

Addressing the question of whether self-leadership strategies could enhance educational learning, development and performance, in the present study, we examined if self-reported self-leadership was predictive of educational attainment (measured through grade average) for a group of business major students. Ours is the first study of selfleadership in an educational context and to examine the association of behavioural, cognitive and motivational (including positive psychological) aspects of self-leadership with attainment.

\section{Method}

\section{Participants}

Participants for the study were 150 students studying various business bachelor and masters programmes at a UK university-based business school. All bachelors were in their second-year of study, masters students were enrolled on a single-year programme. There were 101 women and 49 men in the sample, with a mean age of 21.1 (range 2053; note that 12 students did not report their ages). The students were from a variety of international backgrounds (62.7\% British), and 104 indicated that they had English as a first language.

\section{Measures}

\section{Self-leadership}

We measured self-reported leadership using a set of survey scales. Our novel focus on learning and development (i.e. in place of job performance) necessitated that we write our own survey items rather than use existing measures. We refined the survey scales based on coefficient alpha so that reliability was optimised in short, coherent scales of 3 or 4 items each (with one exception of 2 items). Each item was rated on a five-point scale $(1=$ Almost Never, $2=$ Sometimes, 3 = Frequently, 4 = Almost Always, 5 = Always). The survey included scales measuring five behavioural strategies: goal-setting ( 3 items; e.g. Set myself specific goals for development and learning; $a=.79$ ), monitoring action (4 items; e.g. Monitor my progress towards development objectives; $a=.83$ ), regulating and directing ( 3 items e.g. Take steps to change my learning activities if I feel I will not meet my objectives; $a=.82$ ), constructive dialogue ( 3 items; e.g. Seek others' opinions about my learning and development; $a=.82$ ) and goal-directed behaviour (3items; e.g. Prioritise my activity so that I give sufficient time to my learning goals; $a=.80$ ). We included three cognitive aspects of self-leadership: visualising success ( 3 items; e.g. Visualise myself doing activities successfully before starting them; $a=.77$ ), constructive inner dialogue (self-talk; 3 items; e.g. Have an inner conversation with myself (out loud or in my mind) when I face a challenge; $a=.89$ ) and reflective openness ( 3 items; e.g. Evaluate my learning actions and methods critically in my mind; $a=.85$ ). Finally, we included four scales relating to self-efficacy and positivity: motivational awareness ( 3 items; e.g. Know how to formulate my goals in ways that motivate me; $a=$ .72), self-efficacy for development ( 3 items; e.g. Feel able to make effective decisions about my development; $a=$ .83 ), resilience ( 2 items; e.g. Cope positively with challenges or problems in my learning; $a=.73$ ) and optimism ( 3 items; e.g. Generally feel positive about achieving my learning objectives; $a=.74$ ).

\section{Academic attainment: Grade average}

Module marks were collated for students in the sample. Due to students following different numbers of modules (e.g. as a result of absence or module credit weighting), an average was computed for each student. Module marks were unavailable for nine students in the sample. A total of 118 students in the sample had marks available for 10 separate modules completed during their second year. The remaining 23 students all had marks recorded for a minimum of 3 modules. All modules are marked on a 0-100 scale, and we computed descriptive statistics for the grade average that we used as our attainment criterion ( mean $=61.4$, standard deviation $=8.1$, range $=38.2-84.4$ ). 


\section{Procedure}

We adopted a longitudinal design for the study. The business school at which participants were studying organised the academic year based on a two-semester structure. All participants completed the selfleadership survey within the first 8 weeks of the first semester. Although surveys were completed in class, students were informed that participation was voluntary. Grades were collated at the end of the academic year and comprised marks awarded for assessments completed at the end of semester 1 and 2 . These academic attainment data therefore represent assessments completed around 2-3 months (i.e. end of semester 1 ) and 7-8 months (i.e. end of semester 2 ) after completion of the self-leadership survey.

Results

We ran correlations between grade average and the scales scores for self-rated behavioural, cognitive and motivational self-leadership variables. The results are reported in Table 1.

Our results showed that five aspects of self-leadership were significantly predictive of academic attainment in this sample. These were goal-setting $(r=.23 ; p<.01)$, regulating and directing $(r=.21 ; p<.05)$, goal-directed behaviour $(r=.24 ; p<.01)$, motivational awareness $(r=.18 ; p<.01)$ and optimism $(r=.23 ; p<.05)$. Students who scored higher on these variables, and thereby reported higher use of self-leadership behavioural strategies, being aware of motivational state, and adopting a more positive perspective, performed better in their academic assessments.

We examined the joint effects of behavioural, cognitive and motivational aspects of self-leadership on student grades. To test the distinctiveness of these three components, we entered the 12 self-leadership variables into a principal axis factoring. To determine the number of factors to extract, we conducted parallel analysis (see Goldberg \& Velicer, 2006). This technique models the factor structure of the variables against randomly generated parallel data, with factors retained that are larger (i.e. have higher eigenvalues) than their random-data equivalents. The first four real-data factors had eigenvalues 5.77, 1.07, .51 and .22, and random data .58, .43, .32 and .23. The analyses indicate a three-factor structure. Principal axis factoring specifying a 3 -factor extraction rotated to varimax structure was conducted, and the results are presented in Table 2.

The analyses show that the scales in our survey are structured clearly within behavioural, cognitive and motivational clusters, explaining $71 \%$ of variance in the correlations of the 12 variables. Based on these findings, we created composite variables by taking a mean of the scale scores in each category. For accessibility, we tentatively label these as the 'Doing Self' (behavioural), 'Thinking Self' (cognitive) and 'Energising Self' (motivational).

Table 1. Correlations of all variables in the study.

\begin{tabular}{|c|c|c|c|c|c|c|c|c|c|c|c|c|c|}
\hline & & 1 & 2 & 3 & 4 & 5 & 6 & 7 & 8 & 9 & 10 & 11 & 12 \\
\hline 1. & Goal Setting & & & & & & & & & & & & \\
\hline 2. & Monitoring Action & $.78^{* *}$ & & & & & & & & & & & \\
\hline 3. & $\begin{array}{l}\text { Regulating and } \\
\text { Directing }\end{array}$ & $.71^{* *}$ & $.62^{* *}$ & & & & & & & & & & \\
\hline 4. & $\begin{array}{l}\text { Constructive } \\
\text { Dialogue }\end{array}$ & $.33^{* *}$ & $.39 * *$ & $.39 * *$ & & & & & & & & & \\
\hline 5. & $\begin{array}{l}\text { Goal-directed } \\
\text { Behaviour }\end{array}$ & $.78^{* *}$ & $.69 * *$ & $.71 * *$ & $.44^{* *}$ & & & & & & & & \\
\hline 6. & Visualising Success & $.49 * *$ & $.53^{* *}$ & $.46^{* *}$ & $.31 * *$ & $.43^{* *}$ & & & & & & & \\
\hline & $\begin{array}{l}\text { Constructive Inner } \\
\text { Dialogue }\end{array}$ & $.18^{*}$ & $.26 * *$ & $.21^{*}$ & $.20 *$ & $.18^{*}$ & $.48^{* *}$ & & & & & & \\
\hline 8. & $\begin{array}{l}\text { Reflective } \\
\text { Openness }\end{array}$ & $.47 * *$ & $.61^{* *}$ & $.36^{* *}$ & $.42^{* *}$ & $.37 * *$ & $.55^{* *}$ & $.40 * *$ & & & & & \\
\hline & $\begin{array}{l}\text { Motivational } \\
\text { Awareness }\end{array}$ & $.60 * *$ & $.57^{* *}$ & $.63^{* *}$ & $.29 * *$ & $.57^{* *}$ & $.43 * *$ & .16 & $.44 * *$ & & & & \\
\hline & Self-efficacy & $.55^{* *}$ & $.48^{* *}$ & $.61^{* *}$ & $.25 * *$ & $.55^{* *}$ & $.34 * *$ & .11 & $.31^{* *}$ & $.74 * *$ & & & \\
\hline & Resilience & $.37 * *$ & $.30 * *$ & $.41^{* *}$ & $.26 * *$ & $.34 * *$ & $.19 *$ & .01 & $.18^{*}$ & $.51 * *$ & $.65^{* *}$ & & \\
\hline & Optimism & $.56 * *$ & $.51^{* *}$ & $.60 * *$ & $.23 * *$ & $.54 * *$ & $.39 * *$ & $.20^{*}$ & $.31 * *$ & $.66 * *$ & $.77^{* *}$ & $.50 * *$ & \\
\hline 13. & Grade Average $^{a}$ & $.23 * *$ & .15 & $.21^{*}$ & -.01 & $.24 * *$ & .06 & -.10 & -.02 & $.18^{*}$ & .15 & .06 & $.23 * *$ \\
\hline
\end{tabular}

$\mathrm{aN}=141$; otherwise $\mathrm{N}=150$.

$*_{p}<.05 ; * * p<.01$. 


\begin{tabular}{lccc}
\hline \multicolumn{1}{c}{ Variable } & Factor 1 & Factor 2 & Factor 3 \\
\cline { 2 - 4 } & $\begin{array}{c}\text { The energising self } \\
\text { (motivational) }\end{array}$ & $\begin{array}{c}\text { The doing self } \\
\text { (behavioural) }\end{array}$ & $\begin{array}{c}\text { The thinking self } \\
\text { (cognitive) }\end{array}$ \\
\hline Self-Efficacy & .886 & & \\
Optimism & .800 & & \\
Resilience & .786 & .390 & \\
Motivational Awareness & .731 & .805 & \\
Goal-Directed Behaviour & .373 & .776 & .306 \\
Goal Setting & .410 & .762 & \\
Monitoring Action & .302 & .648 & .677 \\
Regulating and Directing & .520 & .620 & .705 \\
Constructive Dialogue & & .370 & .635 \\
Constructive Inner Dialogue & & .477 & \\
Visualising Success & & & \\
Refletive Openness & & & \\
\hline
\end{tabular}

Note: $\mathrm{N}=150$; Primary Factor loadings in Bold; loadings < .30 omitted.

Table 3.Regression analysis of three components of self-leadership on grade averages.

\begin{tabular}{lcc}
\hline & \multicolumn{2}{c}{ Effects on grade average } \\
\cline { 2 - 3 } & Standardised $b$ & \multicolumn{1}{c}{$t$} \\
\hline The doing self & .25 & $-2.07^{*}$ \\
The thinking self & -.21 & .85 \\
The energising self & .09 & \\
$R$ & .27 & \\
$R^{2}$ & .07 & \\
$F$ & $34.7^{*}$ & \\
\hline
\end{tabular}

$* p<0.05$.

Both the Doing Self and Energising Self correlated significantly with grades (.19 and .18 respectively; $p<.05$ ), and the Thinking Self was not significantly correlated $(-.03 ; p=.75)$. To examine the joint effects of the three composites, we entered them into a multiple regression (see Table 3).

Examination of the beta weights revealed that the Doing Self was positively associated with grades, the Thinking Self negatively associated with grades, and a non-significant positive association for the Energising Self.

\section{Discussion}

Our main objective in this study was to test whether strategies, styles and positive motivational states subsumed under the general framework of self-leadership (Manz, 2015), would predict learning and development in educational settings, measured through average assessment grades in a sample of university students.

Five aspects of self-leadership were correlated with grade average. Three of these represented behavioural strategies of self-leadership; namely goal-setting, regulating and directing, and goal-directed behaviour. Students who more frequently set self-goals for their learning and development, regulated and managed their behaviour if they felt they were not progressing adequately towards their objectives, and also prioritised activity that contributed to annual objectives performed better on average.

These findings are consistent with theories of goal-setting and self. Self-goal setting serves to create goals as internalised desired states, achievement of which drives choice, direction and degree of effort expended in learning activity. It makes sense that goal-directed behaviour (which in our survey related to prioritising behaviour that contributed to goal achievement) was also associated with grade average.

Regulating and directing behaviour represents strategies related to self-regulation. Students who reported more frequently adjusting their approach or strategy if they felt learning goals would not be met tended to perform better 
in their assessments. Interestingly, simply monitoring progress did not predict attainment, the key step appears to be proactively taking steps to change or adjust behaviour in order to address less than satisfactory progress towards objectives.

Among the positive motivational factors, motivational awareness and optimism emerged as significant correlates of grade average. Motivational awareness may be related to self-regulation, in that awareness of energy levels and motivation for a task can prompt behavioural strategies for changing or managing activity. Optimism is concerned with feeling positive generally, but also feeling that success is within one's own control. Although our data do not permit us to ascertain a causative pathway, a potential explanation is that a sense of control is accompanied by a belief that expending effort in learning activity will result in higher grades. People low on optimism may rather feel that their level of attainment is due to external factors such as the questions an examiner sets, or the person who marks their work. Such a perception would discourage engaging in extra effort to increase attainment.

Among the non-significant results, the most notable to discuss are the cognitive variables, because none of the three that we included in the study (visualising success, constructive inner dialogue and reflective openness) were associated with higher attainment in the sample. Our examination of the joint effects of the behavioural, cognitive and motivational components of self-leadership provides further insight.

In the analyses of joint effects, behavioural self-leadership (the Doing Self ) was positively associated with attainment as expected. However, cognitive aspects (the Thinking Self) were negatively associated. How might this counter-intuitive finding be explained? One speculative possibility is that in the context of weaker educational performance or learning strategies, visualisation of success, reflection and encouraging self-talk may be deployed as a form of self-reassurance akin to emotional coping. Focusing on thinking about learning needs at the expense of doing may have negative consequences for performance. Our data do not permit us to probe this issue further, and so clearly future research to disentangle these effects is warranted.

\section{Applied implication for teaching and education}

Our initial question at the outset of this paper was given that research shows the value of self-leadership in people's careers and working lives, could it be similarly valuable in education in University? Ours is the first study to address this question, and our findings allow us to tentatively say yes, there appears to be positive associations of selfleadership with student attainment. In the same way that self-leadership appears to be effective for work performance, so self-leadership may represent behaviours, styles, skills and competencies of self-management that help people to attain more in their education. As a set of strategies for attainment and achievement in education and post-education at work, self-leadership is a compelling prospect.

This represents the most salient and exciting prospect of our findings. If self-leadership has the potential to positively promote learning and effectiveness in education and at work, then training and students to be better self-leaders whilst in education could have wide-ranging benefits throughout their working lives. Given the importance and emphasis of employability in student development, our findings could unlock an important new line of research literature that may have substantial applied benefit in higher education. Strategies of self-leadership have the potential to develop transferable employment-related skills, which could be simultaneously beneficial for educational performance.

Nevertheless, we must acknowledge that there our findings in this study are associational. That is, our data in isolation do not necessarily show that effective self-leadership results in better attainment. Our longitudinal design does enable us to ascertain that students' self-reported use of self-leadership predicts future attainment, yet further research is needed to determine that self-leadership causes that attainment. A logical next step is to examine the effects of self-leadership in an experimental design including pre- and post- measurement of grades and selfleadership, for a control group and experimental group receiving training in self-leadership techniques.

Such training could, for example, develop student optimism with respect to their learning and development focusing on changing the learner's understanding of their current reaction to and interpretation (and cognitive attribution) of adversity. With respect to goal setting, students could be guided to set specific goals and develop the skills to estimate whether goals have the right level of stretch (task difficulty) as well. Students could be encouraged to check 
their level of goal-directed behaviour, and reflect on their level of intention and willingness to prioritise a learning activity against other possible activities. Intervention could also facilitate students to regulate and direct their effort consciously by applying meta-cognitive appraisal (i.e. self-awareness of development progress) and having methods where learners can monitor whether they are on track to reach a goal (including subgoals) or need to adjust, redirect or skip an activity.

\section{Limitations and strengths}

There are two limitations concerning the attainment criterion used. While the overall criterion represented academic attainment over the period of two semesters, it must be acknowledged that students followed somewhat different pathways through their degree subjects. A related point is that by necessarily aggregating performance for the academic year, our analyses could not differentiate between different kinds of assessment. These criterion limitations are relevant to considering the magnitude of the effect sizes reported in our study. In the regression analyses, the overall effect size indicates ca. $7 \%$ of criterion variance explained by the self-leadership variables. Whilst this would be classified as being between a 'small' and a 'medium' effect size in the social sciences (Cohen, 1988), it will be important in future research to understand the effects of various moderators (such as assessment format) to determine if additional variance can be explained by self-leadership.

While acknowledging these limitations, our study also reflected several key strengths. It is the first study to examine self-leadership in the context of higher education learning and development, and our longitudinal design represents an effective research design for examining the predictive, longterm effects of self-leadership behaviour. Moreover, we operationalised self-leadership across multiple aspects specifically oriented towards learning and development.

The key message from our findings is one that if reinforced in further examination of self-leadership in higher education, learners and tutors can apply: set yourself goals, apply your effort to them, be proactive in making changes to your actions if necessary, be aware of your motivation and stay positive. Being an effective self-leader in these ways, in our data, was a predictor of later academic success.

\section{References}

Bandura, A. (1991, August). Self-regulation of motivation through anticipatory and self-reactive mechanisms. Perspectives on motivation: Nebraska symposium on motivation, 38, 69-164.

Cohen, J. (1988). Statistical power analysis for the behavioural sciences. Hillside, NJ: Lawrence Earlbaum Associates.

Dweck, C. S., \& Leggett, E. L. (1988). A social-cognitive approach to motivation and personality. Psychological Review, 95, 256. doi:10.1037/0033-295X.95.2.256

Goldberg, L. R., \& Velicer, W. F. (2006). Principles of exploratory factor analysis. Differentiating normal and abnormal personality, 2, $209-337$.

Gough, D., Kiwan, D., Suttcliffe, K., Simpson, D., \& Houghton, N. (2003). A systematic map and synthesis review of the effectiveness of personal development planning for improving student learning. London: EPPICentre, Social Science Research Unit.

Ho, J., \& Nesbit, P. L. (2014). Self-leadership in a Chinese context: Work outcomes and the moderating role of job autonomy. Group \& Organization Management, 39, 1059. doi:1059601114539389

Latham, G. P., \& Locke, E. A. (2007). New developments in and directions for goal-setting research. European Psychologist, 12, $290-300$. doi:10.1027/1016-9040.12.4.290

Lucke, G. A., \& Furtner, M. R. (2015). Soldiers lead themselves to more success: A self- leadership intervention study. Military Psychology, 27, 311-324. doi:10.1037/mil0000086

Luthans, F., Youssef, C. M., \& Avolio, B. J. (2007). Psychological capital: Developing the human competitive edge. Oxford: Oxford University Press.

Manz, C. C. (2015). Taking the self-leadership high road: Smooth surface or potholes ahead? Academy of Management Perspectives, 29, 132151. doi:10.5465/amp.2013.0060

Marques-Quinteiro, P., \& Curral, L. A. (2012). Goal orientation and work role performance: Predicting adaptive and proactive work role performance through self-leadership strategies. The Journal of Psychology, 146, 559-577. doi:10.1080/0022 3980.2012.656157

Neck, C. P., \& Houghton, J. D. (2006). Two decades of self-leadership theory and research: Past developments, present trends, and future possibilities. Journal of Managerial Psychology, 21, 270-295. doi:10.1108/02683940610663097

Neck, C. P., Houghton, J. D., Sardeshmukh, S. R., Goldsby, M., \& Godwin, J. L. (2013). Self-leadership: A cognitive resource for entrepreneurs. Journal of Small Business \& Entrepreneurship, 26, 463-480. doi:10.1080/08276331.2013.876762 
Payne, S. C., Youngcourt, S. S., \& Beaubien, J. M. (2007). A meta-analytic examination of the goal orientation nomological net. Journal of Applied Psychology, 92, 128-150. doi:10.1037/0021-9010.92.1.128

Peterson, C. (2006). A primer in positive psychology. Oxford: Oxford University Press.

Prussia, G. E., Anderson, J. S., \& Manz, C. C. (1998). Self-leadership and performance outcomes: The mediating influence of self-efficacy. Journal of Organizational Behavior, 19, 523-538. doi:10.1002/(SICI)1099-1379(199809)19:5<523:AIDJOB860>3.0.CO;2-

Schunk, D. H., \& Ertmer, P. A. (1999). Self-regulatory processes during computer skill acquisition: Goal and self-evaluative influences. Journal of Educational Psychology, 91, 251-260. doi:10.1037/0022-0663.91.2.251

Seijts, G. H., Latham, G. P., Tasa, K., \& Latham, B. W. (2004). Goal setting and goal orientation: An integration of two different yet related literatures. Academy of Management Journal, 47, 227-239. doi:10.2307/20159574

Sitzmann, T., \& Johnson, S. K. (2012). The best laid plans: Examining the conditions under which a planning intervention improves learning and reduces attrition. Journal of Applied Psychology, 97, 967-981. doi:10.1037/a0027977

Stewart, G. L., Courtright, S. H., \& Manz, C. C. (2011). Self-leadership: A multilevel review. Journal of Management, 37, $185-222$.

doi:10.1177/0149206310383911

Strivens, J., \& Ward, R. (2013). Reflection as a strategy to enhance students' engagement in their learning. In E. Dunne (Ed.), The student engagement handbook: Practice in higher education. Emerald Group.

Vancouver, J. B., \& Day, D. V. (2005). Industrial and organisation research on self-regulation: From constructs to applications. Applied Psychology, 54, 155-185. doi:10.1111/j.1464-0597.2005.00202.x

Woods, S. A., \& Sofat, J. A. (2013). Personality and engagement at work: The mediating role of psychological meaningfulness. Journal of Applied Social Psychology, 43, 2203-2210. doi:0.1111/jasp.12171

Woods, S. A., \& West, M. A. (2014). The psychology of work and organizations (2nd ed.). Hampshire: CENGAGE 